\title{
Re-examination of the Chinese record of Opisthotropis maculosa (Squamata, Natricidae), resulting in the first national record of $O$. haihaensis and description of a new species
}

\author{
Jian Wang ${ }^{\prime *}$, Zhi-Tong Lyu ${ }^{*}$, Zhao-Chi Zeng', Chao-Yu Lin², Jian-Huan Yang ${ }^{3}$, \\ Truong Quang Nguyen ${ }^{4,5}$, Minh D. Le ${ }^{6,7,8}$, Thomas Ziegler, ${ }^{9}$, Ying-Yong Wang ${ }^{1}$
}

I State Key Laboratory of Biocontrol/The Museum of Biology, School of Life Sciences, Sun Yat-sen University, Guangzhou 510275, China 2 Department of Zoology, Graduate School of Science, Kyoto University, Kyoto 606-8502, Japan 3 Kadoorie Conservation China, Kadoorie Farm and Botanic Garden, Lam Kam Road, Tai Po, Hong Kong, China 4 Institute of Ecology and Biological Resources, Vietnam Academy of Science and Technology, 18 Hoang Quoc Viet, Cau Giay, Hanoi, Vietnam 5 Graduate University of Science and Technology, Vietnam Academy of Science and Technology, 18 Hoang Quoc Viet, Cau Giay, Hanoi, Vietnam 6 Faculty of Environmental Sciences, VNU University of Science, Vietnam National University, Hanoi, 334 Nguyen Trai Road, Hanoi, Vietnam 7 VNU Central Institute for Natural Resources and Environmental Studies, Hanoi National University, 19 Le Thanh Tong, Hanoi, Vietnam 8 Department of Herpetology, American Museum of Natural History, Central Park West at 79 th Street, New York, New York 10024, USA 9 AG Zoologischer Garten Köln, Riehler Strasse 173, D-50735 Cologne, Germany 10 Institute of Zoology, University of Cologne, Zülpicher Strasse 47b, D-50674 Cologne, Germany

Corresponding author: Ying-Yong Wang (wangyy@mail.sysu.edu.cn)

Academic editor: R. Jadin | Received 20 November 2019 | Accepted 16 January 2020 | Published 19 February 2020

http://zoobank.org/768B1F83-557A-4240-8EC2-59AEEC6D4BA8

Citation: Wang J, Lyu Z-T, Zeng Z-C, Lin C-Y, Yang J-H, Nguyen TQ, Le MD, Ziegler T, Wang Y-Y (2020) Reexamination of the Chinese record of Opisthotropis maculosa (Squamata, Natricidae), resulting in the first national record of $O$. haihaensis and description of a new species. ZooKeys 913: 141-159. https://doi.org/10.3897/zookeys.913.48622

\begin{abstract}
The taxonomic status of the previous record of Opisthotropis maculosa Stuart \& Chuaynkern, 2007 from Guangdong and Guangxi, southern China, is revised based on the comparison of morphological and molecular data collected from the Chinese specimens and the holotype of $O$. maculosa from Thailand and O. haihaensis Ziegler, Pham, Nguyen, Nguyen, Wang, Wang, Stuart \& Le, 2019 from Vietnam. Results reveal that the population from Shiwandashan Nature Reserve in southern Guangxi, China belongs to $O$. haihaensis, and represents the first national record for China; the populations from western Guangdong
\end{abstract}

* Contributed equally as the first authors

Copyright Jian Wang et al. This is an open access article distributed under the terms of the Creative Commons Attribution License (CC BY 4.0), which permits unrestricted use, distribution, and reproduction in any medium, provided the original author and source are credited. 
and southeastern Guangxi are described as a new species, Opisthotropis hungtai sp. nov. We suggest that $O$. maculosa should be removed from the Chinese herpetofauna checklist. The new national record of $O$. haihaensis and the description of the new species bring the total number of Opisthotropis to 13 in China.

\section{Keywords}

New national record, Opisthotropis hungtai sp. nov., southern China, taxonomy

\section{Introduction}

The genus Opisthotropis Günther, 1872 currently comprises 23 known species, and has spread widely throughout southern China and mainland of Southeast Asia, eastward to the Ryukyu Archipelago, southward to Sumatra and the Philippines (Ziegler et al. 2008; David et al. 2011, 2015; Yang et al. 2013; Teynié et al. 2014; Wang et al. 2017a, b). Currently, 12 species of the genus have been documented in China: O. andersonii (Boulenger, 1888), O. cheni Zhao, 1999, O. guangxiensis Zhao, Jiang \& Huang, 1978, O. jacobi Angel \& Bourret, 1933, O. kuatunensis Pope, 1928, O. lateralis Boulenger, 1903, O. latouchii (Bouleger, 1899), O. laui Yang, Sung \& Chan, 2013, O. maculosa Stuart \& Chuaynkern, 2007, O. maxwelli Boulenger, 1914, O. shenzhenensis Wang, Guo, Liu, Lyu, Wang, Luo, Sun \& Zhang, 2017, and O. zhaoermii Ren, Wang, Jiang, Guo \& Li, 2017. O. balteata (Cope, 1895) was recently transferred from the genus Opisthotropis to the genus Trimerodytes Cope, 1895 (Ren et al. 2019). Most species of the genus have been well recognized on the basis of phylogenetic and morphological analyses from the type series or topotypic specimens, especially in mainland China and northern Indochina (Ren et al. 2017; Wang et al. 2017; Ziegler et al. 2019). Nevertheless, the taxonomic statuses of several congeners remain unresolved, for instance, the records of $O$. maculosa from Guangdong and Guangxi in southern China (Yang et al. 2011).

Opisthotropis maculosa was originally described based on a single male specimen from northern Thailand (Fig. 1, site 6). Subsequently, it was reported based on morphological identifications in Guangdong (Fig. 1, sites 1,2) and Guangxi (Fig. 1, sites 3,4) in southern China (Yang et al. 2011), and northern Vietnam (Fig. 1, site 5) (Nguyen et al. 2018). Although some minor morphological differences among Chinese, Vietnamese and Thai populations were acknowledged in these publications, molecular data only became available recently, which lead to the resolution of the taxonomic statuses of the Vietnamese and Chinese records of $O$. maculosa. The Vietnamese record of $O$. maculosa was described as a distinct species, O. haihaensis Ziegler, Pham, Nguyen, Nguyen, Wang, Wang, Stuart \& Le, 2019, by comparing the molecular and morphological data with the holotype of $O$. maculosa (Ziegler et al. 2019). In addition, their results also pointed out that the population of $O$. maculosa from Heishiding Nature Reserve in Guangdong, southern China may represent another distinct lineage.

In the present study, the Opisthotropis specimens from Guangdong and Guangxi, southern China previously recorded as O. maculosa, were re-examined using an integra- 


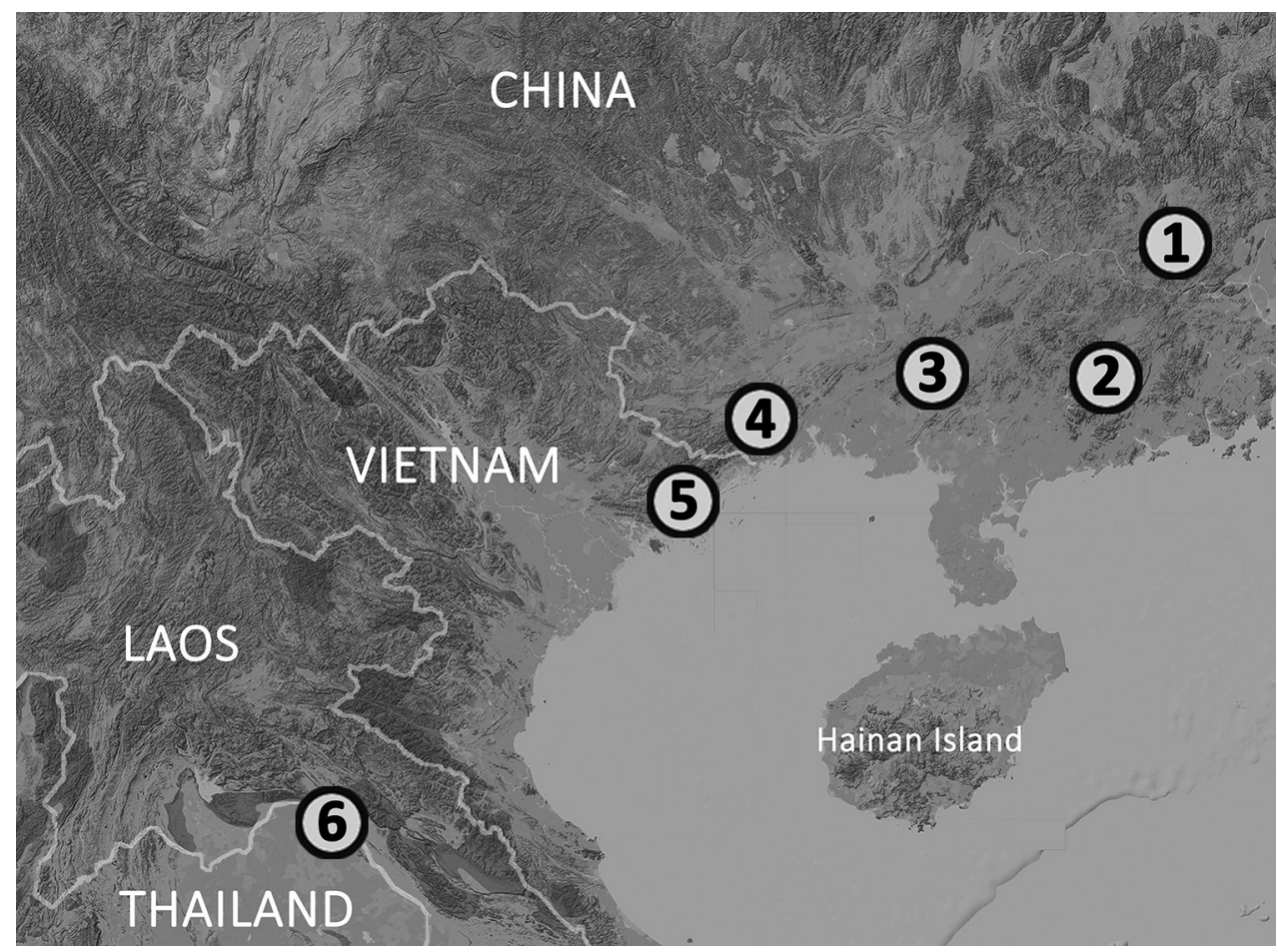

Figure I. Collection localities of Opisthotropis hungtai sp. nov. (1 the type locality, Heishiding Nature Reserve, Guangdong, China 2 Dawuling Forestry Station, Guangdong, China 3 Mt. Wuhuang, Guangxi, China), O. haihaensis (4 Shiwandashan Nature Reserve, Guangxi, China 5 the forest near Tai Chi Village, Quang Ninh, Vietnam) and O. maculosa (6 Phu Wua Wildlife Sanctuary, Nong Khai, Thailand), respectively.

tive taxonomic approach, by combining results from both morphological and molecular analyses. In particular, morphological comparisons among the Chinese ' $O$. maculosa', the true $O$. maculosa from Thailand and the recently described $O$. haihaensis from Vietnam were undertaken in detail. The results demonstrate that the populations from southeastern Guangxi and western Guangdong represent a distinct taxon, which is described as a new species; the population from southern Guangxi is identified as O. haihaensis.

\section{Material and methods}

\section{Morphometrics}

Morphological examinations were performed on the holotype of Opisthotropis haihaensis, specimens reported as O. maculosa by Yang et al. (2011), and several other newly collected specimens. The collection information is given in the taxonomy accounts below. All specimens were fixed in $10 \%$ buffered formalin and later transferred to $70 \%$ ethanol for preservation, and deposited in the Museum of Biology, Sun Yat-sen 
University (SYS), Kadoorie Farm and Botanic Garden (KFBG), and Institute of Ecology and Biological Resources, Hanoi, Vietnam (IEBR).

Measurements followed Wang et al. (2017) and Ziegler et al. (2019) and were taken with digital calipers to the nearest $0.1 \mathrm{~mm}$. These measurements were as follows:

TL total length (from tip of snout to tip of tail);

SVL snout-vent length (from tip of snout to posterior margin of cloacal plate);

TaL tail length (from posterior margin of cloacal plate to tip of tail).

Scalation features and their abbreviations are as follows: preoculars ( $\mathbf{P r O})$; postoculars (PtO); supralabials (SPL); infralabials (IFL); temporals (TMP); ventral scales (V); subcaudals (SC); dorsal scale rows (DSR) were counted at one head length behind head, at midbody, and at one head length before vent, respectively. Bilateral scale counts were given as left/right.

Maxillary teeth counts (MT) were determined by subequal teeth or sockets on right upper maxilla, and sex was determined by dissection or by the presence/absence of everted hemipenis.

\section{Phylogenetic analyses}

The mitochondrial cytochrome $b$ (CYTB) gene was used for molecular analyses. Two new samples from Mt. Wuhuang, southeastern Guangxi and Shiwandashan Nature Reserve, southwestern Guangxi, were included in our study. DNA extraction, PCR amplification and sequencing followed the protocol employed by Wang et al. (2017). In addition, 31 Opisthotropis and two outgroup sequences (following Ziegler et al. 2019) were attained from GenBank for the phylogenetic analysis (Table 1).

Amino acid sequences for the CYTB gene of all samples were first aligned using Clustal W with default parameters. After checking the alignment to make sure that there was no stop or error codon, the amino acid sequence dataset was transformed to a nucleotide sequence dataset. We then applied JModelTest v2.1.2 on the nucleotide sequence dataset under Akaike and Bayesian information criteria to determine the bestfit nucleotide substitution model. The dataset was analyzed using maximum likelihood (ML) in RaxmlGUI 1.3 (Silvestro and Michalak 2012) and Bayesian inference (BI) in MrBayes 3.2 (Ronquist et al. 2012) with the GTR + I + G model. For ML analysis, a bootstrap consensus tree inferred from 1000 replicates was used to represent the evolutionary history of the taxa analyzed. Branches reproduced in less than $50 \%$ of bootstrap replicates were collapsed. For BI analysis, two independent runs with four Markov Chain Monte Carlo simulations were performed for ten million iterations and sampled for every $1000^{\text {th }}$ iteration. The first $25 \%$ of samples were discarded as burn-in. Convergence of the Markov Chain Monte Carlo simulations was assessed using Tracer v.1.4 (http://tree.bio.ed.ac.uk/software/tracer/). We also calculated pairwise sequence divergence based on uncorrected $p$-distance using MEGA 6.06 (Tamura et al. 2013). 
Table I. Localities, voucher information, and GenBank numbers for all samples used in this study.

\begin{tabular}{|c|c|c|c|c|}
\hline ID & Opisthotropis Species & Voucher No. & Collection locality & Genbank No. \\
\hline 1 & $\begin{array}{l}\text { Opisthotropis hungtai } \\
\text { sp. nov. }\end{array}$ & SYS r000538 (Paratype) & CHINA: Guangxi: Mt. Wuhuang & MN890018 \\
\hline 2 & $\begin{array}{l}\text { Opisthotropis hungtai } \\
\text { sp. nov. }\end{array}$ & SYS r000946 (Holotype) & $\begin{array}{l}\text { CHINA: Guangdong: Heishiding } \\
\text { Nature Reserve }\end{array}$ & KY594748 \\
\hline 3 & O. andersonii & SYS r001423 (Topotype) & CHINA: Hongkong: Tai Tam & KY594730 \\
\hline 4 & O. andersonii & SYS r001424 (Topotype) & CHINA: Hongkong: Tai Mo Shan & KY594731 \\
\hline 5 & O. cheni & YBU071040 (Topotype) & $\begin{array}{l}\text { CHINA: Hunan: Mangshan Nature } \\
\text { Reserve }\end{array}$ & GQ281779 \\
\hline 6 & O. cheni & SYS r001422 & $\begin{array}{l}\text { CHINA: Guangdong: Shimentai } \\
\text { Nature Reserve }\end{array}$ & KY594741 \\
\hline 7 & O. daovantieni & ROM FS39306 & VIETNAM & MK941140 \\
\hline 8 & O. durandi & NCSM 80739 & VIETNAM & MK941137 \\
\hline 9 & O. guangxiensis & GP746 & CHINA: Guangxi & GQ281776 \\
\hline 10 & O. haihaensis & $\begin{array}{l}\text { IEBR A.2016.34 } \\
\text { (Holotype) }\end{array}$ & $\begin{array}{l}\text { VIETNAM: Quang Ninh: Hai Ha } \\
\text { District }\end{array}$ & MK991139 \\
\hline 11 & O. haihaensis & SYS r000537 & $\begin{array}{l}\text { CHINA: Guangxi: Shiwandashan } \\
\text { Nature Reserve }\end{array}$ & MN890017 \\
\hline 12 & O. jacobi & IEBR 4329 & VIETNAM: Vinh Phuc: Tam Dao & MG545601 \\
\hline 13 & O. jacobi & ZFMK 100818 & VIETNAM: Vinh Phuc: Tam Dao & MG545602 \\
\hline 14 & O. kuatunensis & SYS r001008 & CHINA: Fujian: Shanghang County & KY594746 \\
\hline 15 & O. kuatunensis & SYS r001081 & CHINA: Guangdong: Mt. Wutong & KY594747 \\
\hline 16 & O. laui & SYS r001161 & $\begin{array}{l}\text { CHINA: Guangdong: Shangchuan } \\
\text { Island }\end{array}$ & KY594738 \\
\hline 17 & O. laui & SYS r001170 & $\begin{array}{l}\text { CHINA: Guangdong: Shangchuan } \\
\text { Island }\end{array}$ & KY594739 \\
\hline 18 & O. lateralis & SYS r000951 & $\begin{array}{l}\text { CHINA: Guangdong: Heishiding } \\
\text { Nature Reserve }\end{array}$ & KY594743 \\
\hline 19 & O. lateralis & SYS r001080 & CHINA: Guangdong: Mt. Wutong & KY594744 \\
\hline 20 & O. lateralis & - & CHINA: Guangxi & GQ281782 \\
\hline 21 & O. latouchii & SYS r000670 (Topotype) & CHINA: Fujian: Mt. Wuyi & KY594742 \\
\hline 22 & O. latouchii & GP647 & CHINA: Fujian & GQ281783 \\
\hline 23 & O. maculosa & $\begin{array}{c}\text { FMNH } 265798 \\
\text { (Holotype) }\end{array}$ & $\begin{array}{l}\text { THAILAND: Nong Khai: Phu Wua } \\
\text { Wildlife Sanctuary }\end{array}$ & MK991138 \\
\hline 24 & O. maxwelli & SYS r000841 & CHINA: Guangdong: Nan'ao Island & KY594736 \\
\hline 25 & O. maxwelli & SYS r001053 & $\begin{array}{l}\text { CHINA: Fujian: Huboliao Nature } \\
\text { Reserve }\end{array}$ & KY594737 \\
\hline 26 & O. shenzhenensis & SYS r001018 (Holotype) & CHINA: Guangdong: Mt. Wutong & KY594727 \\
\hline 27 & O. shenzhenensis & SYS r001021 (Paratype) & CHINA: Guangdong: Mt. Sanzhoutian & KY594728 \\
\hline 28 & O. shenzhenensis & SYS r001032 (Paratype) & CHINA: Guangdong: Mt. Tiantou & KY594729 \\
\hline 29 & O. voquyi & ZFMK 100819 (Paratype) & $\begin{array}{l}\text { VIETNAM: Bac Giang: Tay Yen Tu } \\
\text { Nature Reserve }\end{array}$ & MG451049 \\
\hline 30 & O. voquyi & ZFMK 100820 (Paratype) & $\begin{array}{l}\text { VIETNAM: Bac Giang: Tay Yen Tu } \\
\text { Nature Reserve }\end{array}$ & MG451050 \\
\hline 31 & O. zhaoermii & CIB109998 (Paratype) & CHINA: Hunan: Guzhang County & MG012799 \\
\hline 32 & O. zhaoermii & CIB109999 (Holotype) & CHINA: Hunan: Guzhang County & MG012800 \\
\hline 33 & O. zhaoermii & CIB110000 (Paratype) & CHINA: Hunan: Guzhang County & MG012801 \\
\hline \multicolumn{5}{|c|}{ Outgroups } \\
\hline 34 & $\begin{array}{l}\text { Aspidura } \\
\text { drummondhayi }\end{array}$ & RS-M & SRI LANKA: Nuwara Eliya & KC347455 \\
\hline 35 & Aspidura trachyprocta & RS-134 & SRI LANKA: Nuwara Eliya & KC347458 \\
\hline
\end{tabular}




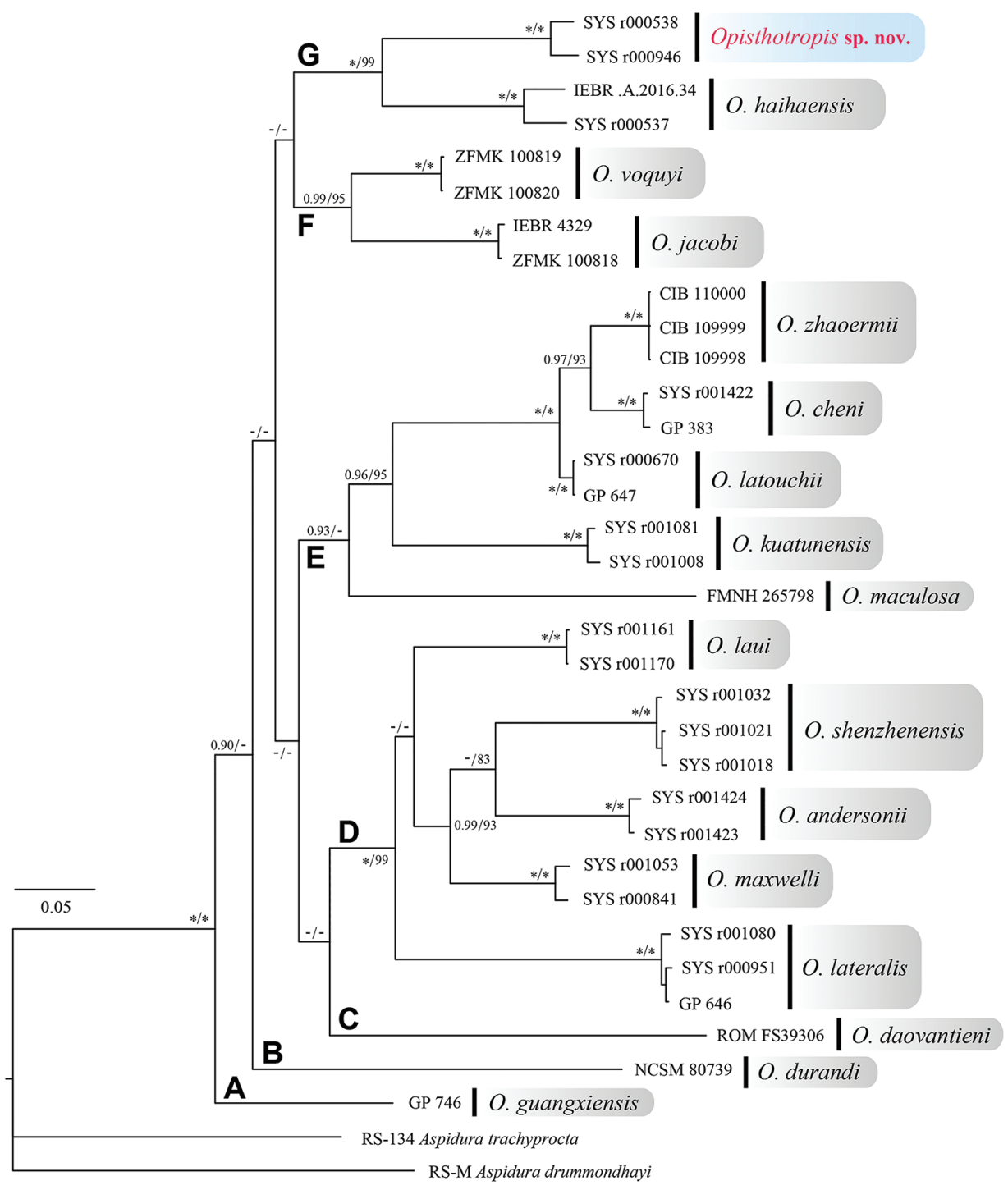

Figure 2. Bayesian Inference and Maximum Likelihood phylogenies. The Bayesian posterior probabilities $(\mathrm{BPP})>0.90$ and the bootstrap supports for Maximum Likelihood analysis $(\mathrm{BS})>80$ were retained.

\section{Results}

The CYTB nucleotide sequence matrix contained 1059 characters without insertiondeletions. The MP and BI analyses produced essentially identical topologies, which were integrated in Fig. 2. Major nodes of the tree were sufficiently supported, with Bayesian posterior probabilities (BPP) $>0.90$ and bootstrap supports (BS) for maximum likelihood analysis $>80$. Uncorrected $p$-distances among Opisthotropis species based on the CYTB gene are shown in Table 2. 


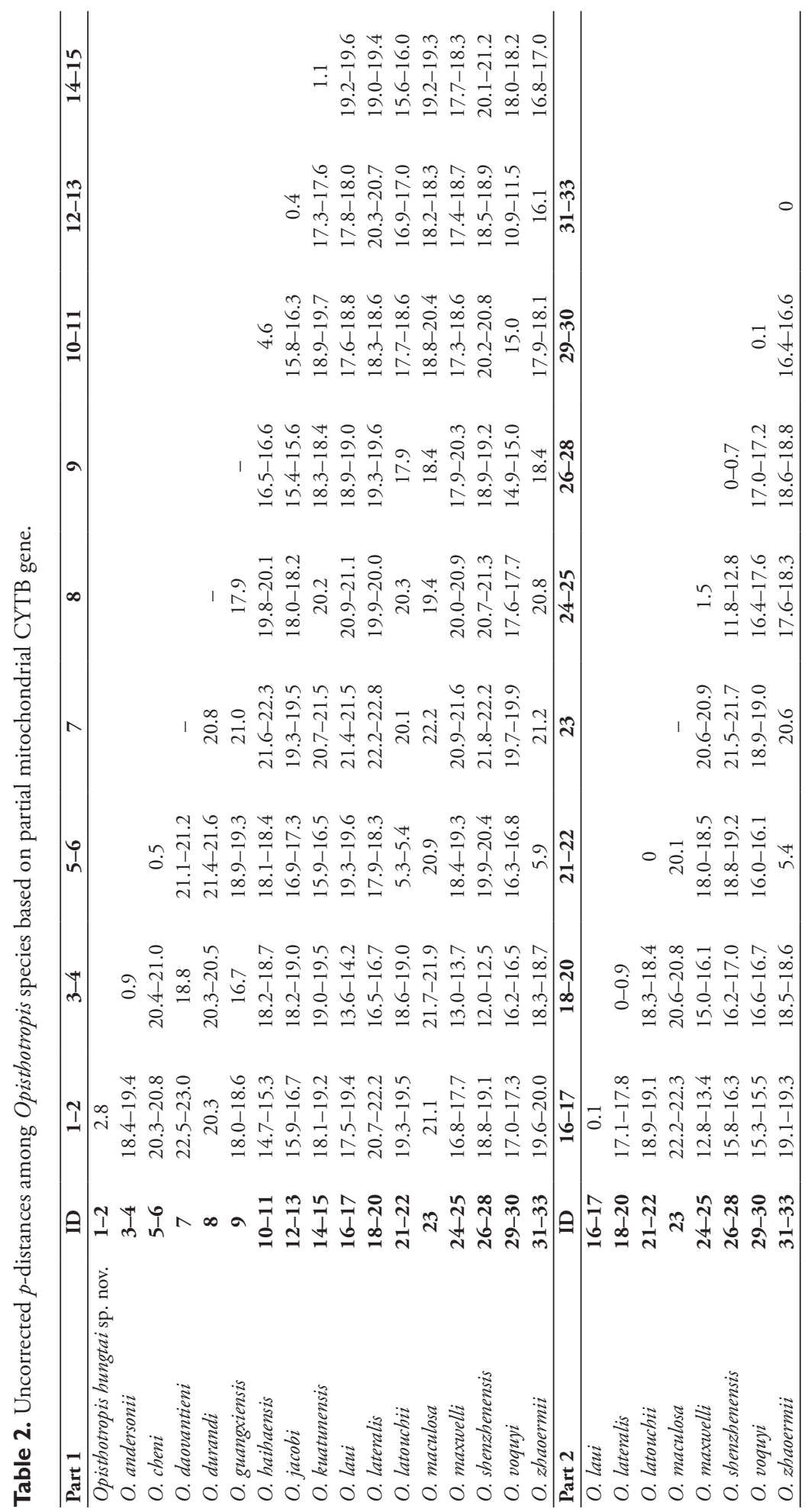


In our phylogenetic tree, all samples of the genus Opisthotropis clustered in a monophyletic group with high nodal supports (BPP 1.00 and BS 100), and can be divided into seven clades, although the relationships among these clades were unresolved. Opisthotropis daovantieni Orlov, Darevsky \& Murphy, 1998, O. durandi Teynié, Lottier, David, Nguyen \& Vogel, 2014 and O. guangxiensis formed three monotypic clades, respectively. Opisthotropis andersonii, O. lateralis, O. laui, O. maxwelli, and O. shenzhenensis were grouped in clade D (BPP 1.00 and BS 99). Clade E (BPP 0.93) contained O. cheni, O. kuatunensis, O. latouchii, the true $O$. maculosa, and $O$. zhaoermii. The sister species O. jacobi and O. voquyi Ziegler, David, Ziegler, Pham, Nguyen \& Le, 2018 constituted clade F (BPP 0.99 and BS 95).

Within clade G (BPP 1.00 and BS 99), the Opisthotropis sample (SYS r000537) from Shiwandashan Nature Reserve, southern Guangxi, was placed with the holotype of $O$. haihaensis from northeastern Vietnam, with high node support values (BPP 1.00 and BS 100) and moderate genetic distance ( $p$-distance 4.6\%). The detailed morphological examination suggests that they represent individuals of the same species. Thus, we herein revise the identification of the specimen as $O$. haihaensis, and report it as a new national record for China.

Besides, the Opisthotropis samples from Mt. Wuhuang, southeastern Guangxi and Heishiding Nature Reserve, western Guangdong, were reconstructed as a monophyletic clade with strong nodal supports (BPP 1.00 and BS 100) and small genetic distance ( $p$-distance 2.8\%). The populations should be considered as a distinct taxon, which is sister to $O$. haihaensis. These specimens show almost no morphological differences from those collected at Dawuling Forestry Station, western Guangdong, which is located in the same mountain belt as Heishiding Nature Reserve. Therefore, we describe these specimens as a new species, Opisthotropis hungtai sp. nov.

\section{Taxonomy accounts}

\section{Opisthotropis haibaensis Ziegler, Pham, Nguyen, Nguyen, Wang, Wang, Stuart \& Le, 2019}

Figures 3,5A

Chresonymy. Opisthotropis maculosa Stuart \& Chuaynkern, 2007: Yang et al. (2011) (part); Nguyen et al. (2018).

Holotype. IEBR A.2016.34 [Field No. QN 2016.91], adult female, from the forest near Tai Chi Village, Quang Son Commune, Hai Ha District, Quang Ninh Province, $950 \mathrm{~m}$ asl., Vietnam [exact locality and coordinates not provided owing to threat from collection for the pet trade (Ziegler et al. 2019)], collected by Cuong The Pham and Tan Van Nguyen on 9 May 2016.

Specimens examined $(\mathbf{N}=\mathbf{1})$. SYS a000537, adult female, collected by Qing Du and Jian-Huan Yang on 10 July 2009 from Shiwandashan Nature Reserve [exact coordinates not provided owing to threat from collection for the pet trade], Shangsi County, Qinzhou City, Guangxi Zhuang Autonomous Region, 493 m a.s.l., P.R. China. 


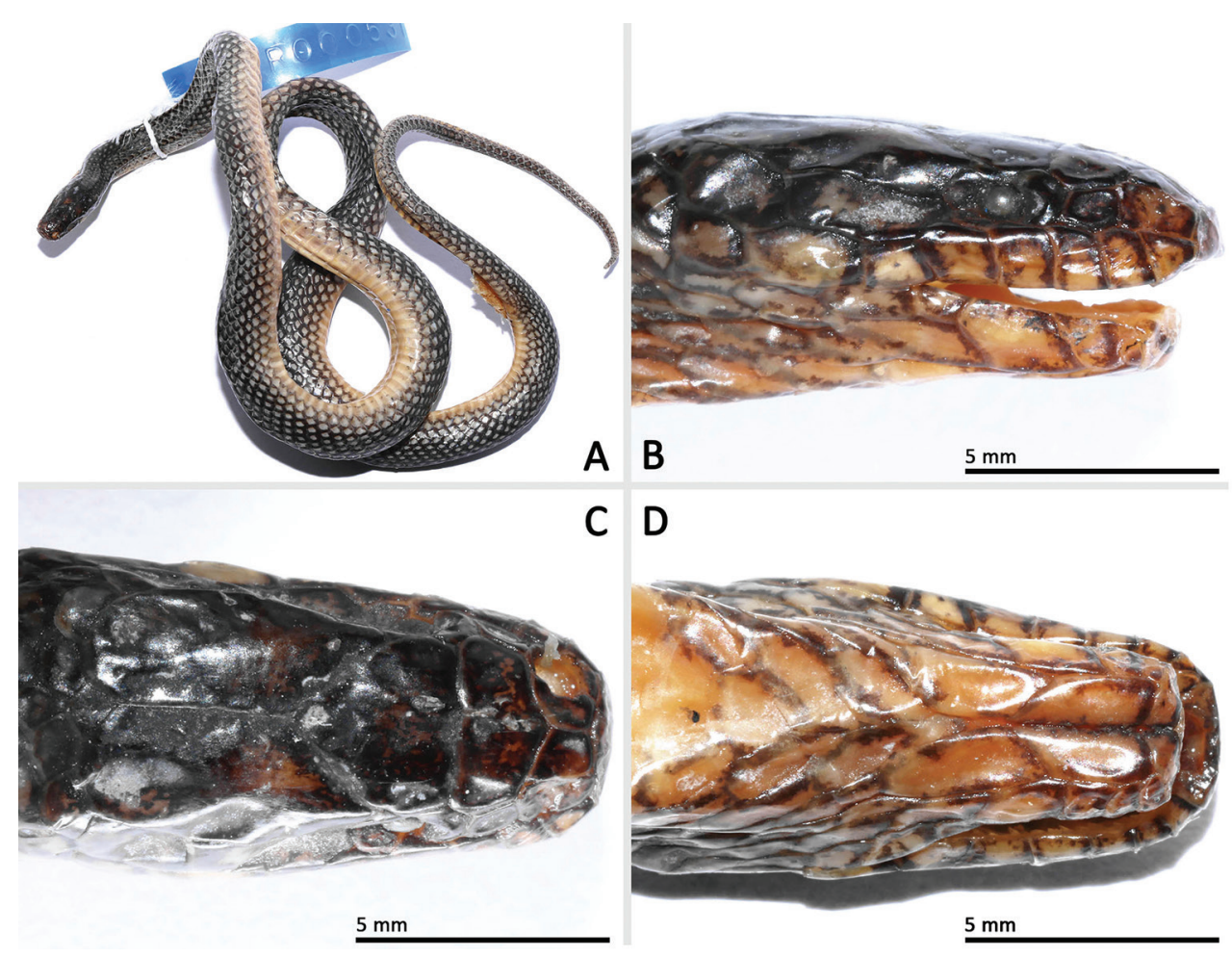

Figure 3. Morphological features of Opisthotropis haihaensis (SYS r000537) from Shiwandashan Nature Reserve, Guangxi, China. A Habitus view B-D close-up of head scales. Photos by Jian Wang.

Etymology. According to the original description, the specific name "haihaensis" refers to the type locality of this species, Haiha District (Quang Ninh Province) in Vietnam. As this species is currently reported in China, we suggest its Chinese name “Hai He Hou Leng She (海河后棱蛇)", derived from its scientific name.

Variation. Measurements, scalation and body proportions of the two specimens are listed in Table 3. The specimen from China conforms to the holotype from Vietnam except for: (1) a shorter body size: snout-vent length $391.3 \mathrm{~mm}$, tail length $108.9 \mathrm{~mm}$ (vs. SVL $396 \mathrm{~mm}$, Tal $113 \mathrm{~mm}$ in the holotype); (2) a higher number of postoculars: $\mathrm{PtO} 2$ (vs. $\mathrm{PtO} 1$ in the holotype); (3) a lower number of maxillary teeth: MT 22 (vs. MT 24 in the holotype); (4) a lower number of ventrals: V 164+2 (vs. V 169+2 in the holotype); (5) a lower number of subcaudals: SC 75 (vs. SC 79 in the holotype); and (6) tail scales indistinctly keeled (vs. tail scales smooth in the holotype).

Revision of original diagnosis. Opisthotropis haihaensis is characterized by the combination of the following characters: (1) TL 500.2-509 $\mathrm{mm}$ in adult females, (2) tail relatively long, TaL/TL 0.22 , (3) internasal not in contact with loreal, prefrontal not touching supraocular, frontal touching preocular, (4) one preocular, one or two postocular(s), (5) temporals $1+1$, (6) supralabials eight, fourth and fifth in contact with eye, (6) 22-24 maxillary teeth, (7) anterior pair of chin shields longer than posterior 


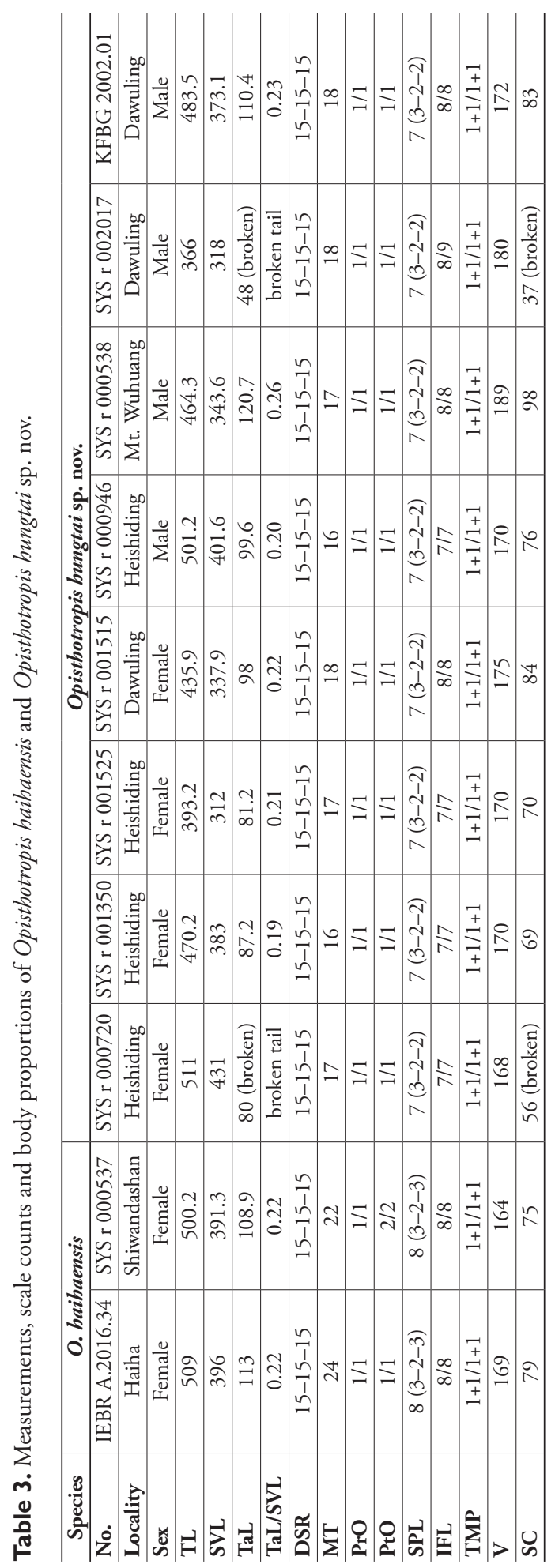


pair; (8) ventrals 164-169 (+ 2 preventrals), (9) subcaudals 75-79, (9) nasal cleft pointing to the first supralabial, (10) body scales in 15-15-15 rows, (11) body scales smooth, tail scales smooth or indistinctly keeled, (12) chin shields yellow with brownish black mottling, and (13) body and tail dorsum dark, each with a light yellow spot per scale.

Coloration in life (SYS r000537). Eye black; scales on dorsal surface of head glossy black with scattered yellow flecking; chin shields yellow with brownish black mottling; body and tail glossy black with iridescence above, with single yellow spot on each scale, yellow spots becoming larger on sides of body; ventrals yellow with brownish black lateral margins and scattered brown flecks; subcaudals yellow with brownish black anterior and lateral margins in both specimens.

Coloration in preservation (SYS r000537). Ground color of upper head and body surface dark brown, that of venter yellowish-beige. Dorsal scales each with light blotch in the center. Dorsal tail scales likewise with light central blotches. Dorsal head surface in part with indistinct light mottling. Anterior supralabials with large light mottling. Infralabials, chin shields and smaller throat scales anterior to ventrals yellowish-beige with dark brown mottling per scale. Belly with few, scattered dark flecks on sides. Outermost edges of light ventrals brown. Ground color of subcaudals brown with transversally enlarged light blotches at each scale end.

Distribution and habits. Opisthotropis haihaensis is currently known from its type locality, the forest near Tai Chi Village (ca 950 m a.s.l.), Quang Ninh, northern Vietnam, and Shiwandashan Nature Reserve (ca 500 m a.s.l.), southwestern Guangxi, southern China. The straight-line distance between the two localities is approximately 150 kilometers, indicating that the distribution area of this species is the mountain region on the border between China and Vietnam.

The holotype was found at night in a small rocky stream at 21:30h. The surrounding habitat was secondary evergreen forest consisting of small hardwoods, bamboo, and shrubs. The air temperature was $24-29^{\circ} \mathrm{C}$ and the relative humidity was $65-88 \%$. The holotype revealed to be an adult female, as dissection showed up to $16.5 \mathrm{~mm}$ long eggs and the oviducts were folded, indicating that eggs had already been laid (Ziegler et al. 2019). Besides, the other specimen, SYS r000537, was collected from a rocky stream (about $8 \mathrm{~m}$ wide and $0.3 \mathrm{~m}$ deep at the collecting site) running through wellpreserved, dense deciduous forests. The collected individual was spotted swimming at night and swiftly hiding under stones when disturbed.

\section{Opisthotropis hungtai sp. nov.}

http://zoobank.org/A0FC2C8F-866B-4D81-9237-1E42942711AA

Figures 4, 5B, 6

Chresonymy. Opisthotropis maculosa Stuart \& Chuaynkern, 2007: Yang et al. (2011) (part); Wang et al. (2017a), Ren et al. (2019).

Holotype. SYS r000946, adult male, collected by Jian Zhao on 2 September 2014 from Heishiding Nature Reserve [exact coordinates not provided owing to threat 

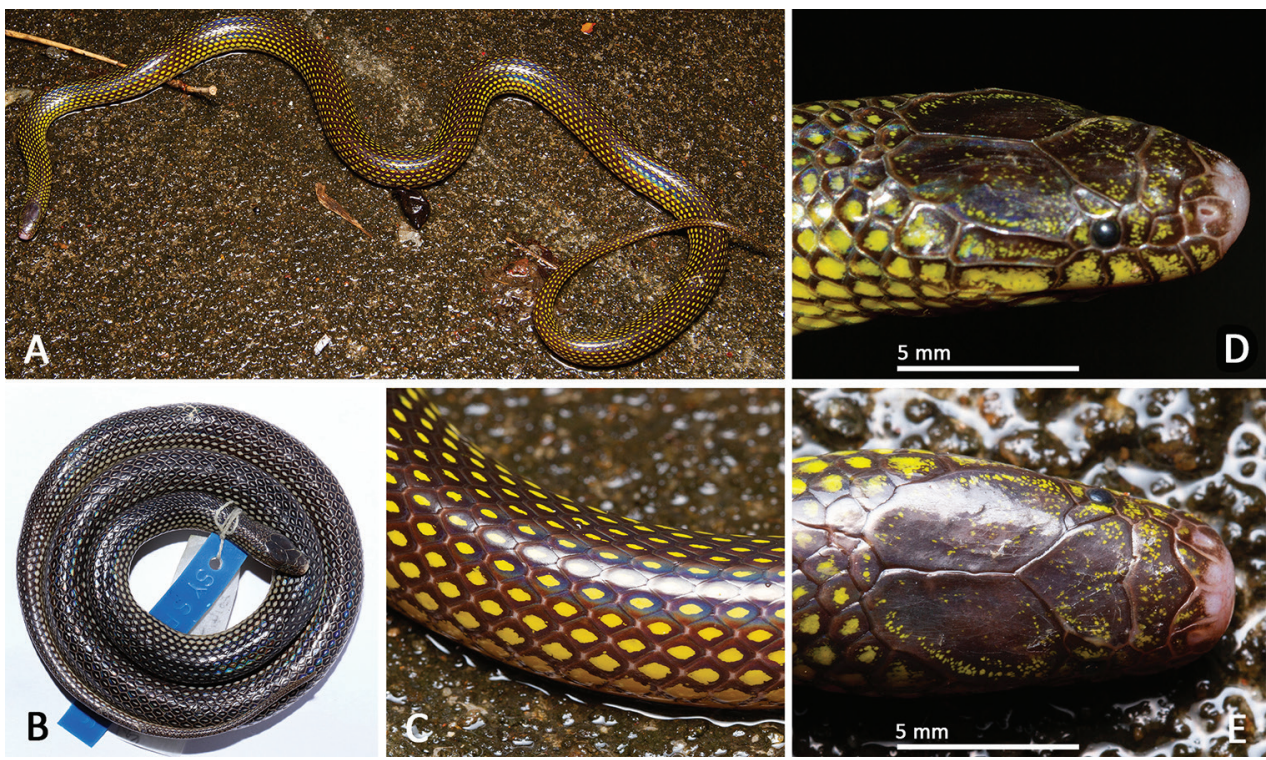

Figure 4. Morphological features of the adult male holotype SYS r00946 of Opisthotropis hungtai sp. nov. A Habitus view in life B habitus view in preservative $\mathbf{C}$ close-up of mid-dorsal body $\mathbf{D}-\mathbf{E}$ close-up of head scales. Photos by Jian Zhao and Jian Wang.

from collection for the pet trade, same as paratypes], Fengkai County, Zhaoqing City, Guangdong Province, $300 \mathrm{~m}$ a.s.l., P.R. China.

Paratypes $(\mathbf{N}=7)$. Adult female SYS r001350 collected by Zhi-Tong Lyu on 15 August 2015, adult female SYS r000720 collected by Ying-Yong Wang on 28 June 2012, and adult female SYS r001525 collected by Zhi-Tong Lyu and Ying-Yong Wang on 1 July 2016, from the same locality as the holotype. Adult male KFBG 2002.01 collected by Zhi Xiao on 2 July 2002, adult male SYS r002017 collected by Jian Wang on 14 June 2018, and adult male SYS a001515 collected by Jian Wang on 8 July 2017, all from Dawuling Forestry Station, Xinyi City, Maoming City, Guangdong Province, ca 1150 m a.s.l., P.R. China. Adult male SYS a000538, collected by Qing Du and Runlin Li on 14 July 2009 from Mt. Wuhuang, Pubei County, Qinzhou City, Guangxi Zhuang Autonomous Region, ca 360 m a.s.l., P.R. China.

Etymology. The species name "hungtai" refers to Professor Hung-Ta Chang (=Hong-Da Zhang, 张宏达), an outstanding botanist, who established the Tropical and Subtropical Forest Ecosystem Experimental Center in Heishiding Nature Reserve, promoting the development of ecological research in southern China. We suggest the English common name Hung-Ta Chang's mountain Keelback and the Chinese name Zhang Shi Hou Leng She (张氏后棱蛇).

Diagnosis. Opisthotropis hungtai sp. nov. is characterized by the following combination of characters: (1) TL 464.3-501.2 $\mathrm{mm}$ in adult males, 393.2-511 $\mathrm{mm}$ in females, (2) tail moderate, TaL/TL 0.20-0.26 in males, 0.19-0.22 in females, (3) internasal not in contact with loreal, prefrontal not touching supraocular, frontal touching preocular, (4) one pre- 
ocular, one or two postocular(s), (5) temporals $1+1,(6)$ supralabials seven, the fourth and fifth in contact with eye; (6) maxillary teeth 16-18, (7) anterior pair of chin shields longer than or equal to posterior pair; (8) ventrals 170-189 (+ 2 preventrals) in males, 168-175 (+ 2 preventrals) in females, (9) subcaudals 76-98 in males, 69-84 in females, (9) nasal cleft pointing to the second supralabial, (10) body scale in 15-15-15 rows, (11) body scales smooth, tail scales smooth or indistinctly keeled, (12) chin shields yellow with brownish black mottling, and (13) body and tail dorsum dark, each with a light spot per scale.

Comparisons. Opisthotropis hungtai sp. nov. is compared with $O$. maculosa and $O$. haihaensis, which share a very similar appearance. Measurements, scalation and body proportions of $O$. haihaensis and Opisthotropis hungtai sp. nov. are listed in Table 3.

Opisthotropis hungtai sp. nov. differs from $O$. maculosa by prefrontal not touching supraocular (vs. prefrontal touching supraocular in $O$. maculosa), by frontal touching preocular (vs. frontal not touching preocular in $O$. maculosa), by fourth and fifth supralabials in contact with eye (vs. fourth supralabial in contact with eye in $O$. maculosa), by anterior pair of chin shields longer than or equal to posterior pair (vs. anterior pair of chin shields shorter than posterior pair in $O$. maculosa), by a higher number of subcaudals, 76-98 in males (vs. 67 in the single male holotype of $O$. maculosa), and by chin shields yellow with brownish black mottling (vs. immaculate in O. maculosa).

Opisthotropis hungtai sp. nov. differs from $O$. haihaensis by having seven supralabials, the second last one significantly enlarged, narrow and long, significantly wider than high (vs. eight supralabials, the second last one slightly enlarged, slightly wider than high in O. haihaensis) (Fig. 5), and MT 16-18 (vs. MT 22-24 in O. haihaensis).

Description of holotype. Body cylindrical, slender, round to oval in cross section; TL $501.2 \mathrm{~mm}$ (SVL $401.6 \mathrm{~mm}$, TaL $99.6 \mathrm{~mm}$ ); tail thin and pointed, TaL 20\% of TL; head small, indistinct from neck; right upper maxilla with 16 subequal teeth or sockets, teeth small, curved, without diastema; rostral nearly flattened, small, slightly less than twice as broad as deep, barely visible from above; two internasals, crescent-shaped, in contact with each other medially behind the rostral, not in contact with loreal, posteriorly in contact with prefrontal; a single prefrontal, in contact with loreal and preocular laterally, with frontal posteriorly, not in contact with supraocular; a single frontal, hexagonal, in contact with supraocular laterally, with two parietals posteriorly; parietals large, in contact with each other medially; nasal directed dorsally, polygonal, in contact with first and second supralabials ventrally, with loreal and prefrontal posteriorly, with internasal dorsally, with rostral anteriorly; nostril horizontally oval, in the upper part of nasal; a short vertical cleft below the nostril and dividing nasal into anterior and posterior parts, pointing to middle of upper edge of second supralabial; a single loreal, trapezoid, not entering the orbit, in contact with second and third supralabials laterally; a single supraocular, much longer than wide, obliquely set; a single preocular, higher than wide, in contact with frontal; a single postocular; a single anterior temporal, significantly elongate, in broad contact with the elongated sixth supralabial; a single posterior temporal, pentagonal; supralabials $7 / 7$, the sixth one significantly elongate, the last one much shorter than the adjacent preceding supralabial; fourth and fifth supralabials entering orbit; infralabials $7 / 7$, the first one in contact with its fellow behind the mental; two pairs of chin shields; anterior chin 


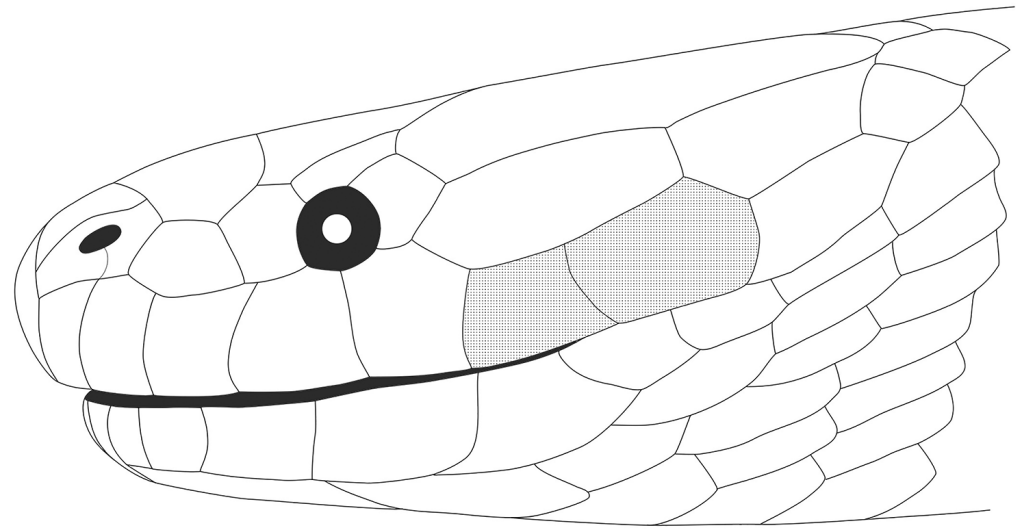

A. Opisthotropis haihaensis (IEBR A.2016.34)

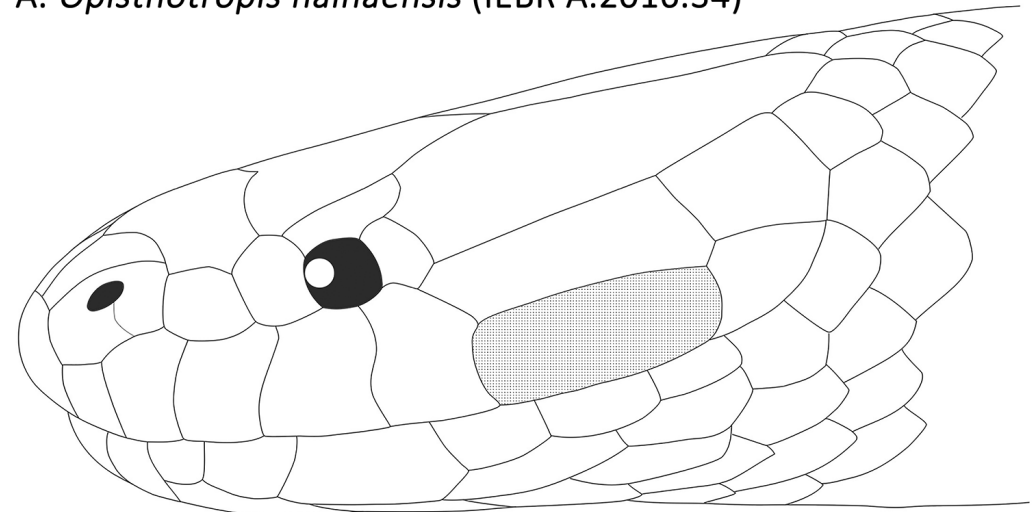

B. Opisthotropis hungtai sp. nov.(SYS r000946)

Figure 5. Comparisons of head scalation of Opisthotropis haihaensis and Opisthotropis hungtai sp. nov. Line illustration by Zhi-Tong Lyu.

shields larger, in contact with each other medially, and in contact with the first four infralabials on both sides; posterior chin shields smaller, in contact with each other; dorsal scales in 15-15-15 rows; dorsal scales of body smooth throughout; dorsal scales of tail weakly keeled; ventrals 170; cloacal plate divided; subcaudals 76, paired.

Coloration of holotype in life. Eye black; scales on dorsal surface of head glossy dark brown with scattered yellow flecking; chin shields yellow with brownish black mottling at each margin; body and tail glossy dark brown with single yellow spot on each scale, yellow spots becoming larger on sides of body; ventrals yellow with brownish black lateral margins and few scattered brown flecks; subcaudals yellow with brownish black anterior and lateral margins.

Coloration of holotype in preservative. Ground color of upper head and body surface dark brown (Fig. 4B), that of venter yellowish-beige. Dorsal scales each with 

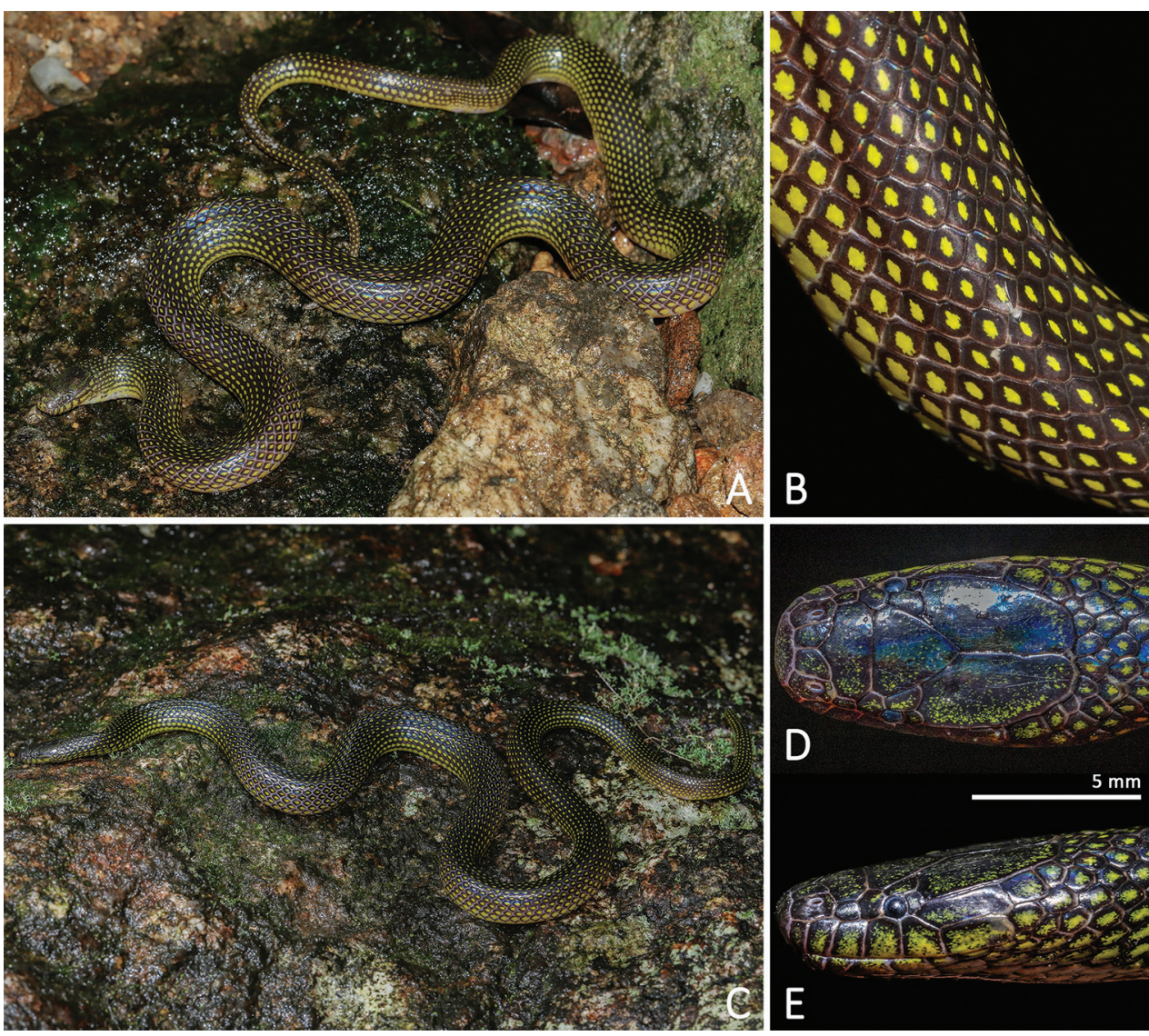

Figure 6. Morphological features of the adult female paratypes of Opisthotropis hungtai sp. nov. from Dawuling Forestry Station, Guangdong, China. A, B Habitus view and close-up of mid-dorsal body of SYS r001515 C-E habitus view and close-up of head scales of SYS r002017. Photos by Jian Wang.

light yellow blotch in the center. Dorsal blotches almost equal in size. Blotches becoming wider towards body sides; largest at outermost dorsal scale row, where the light blotches stretch towards the posterior scale end. Dorsal tail scales likewise with light central blotches. Dorsal head surface in part with indistinct light mottling that becomes more obvious on temporals. All supralabials with a light blotch. Infralabials, chin shields and smaller throat scales anterior to ventrals light yellow with brown mottling/blotches per scale. Belly with few, scattered dark flecks. Outermost edges of light ventrals brown. Ground color of subcaudals light yellow with black anterior and lateral margins.

Variations. Measurements, body proportions and scale counts are listed in Table 3. All paratype specimens are very similar to the holotype in appearance (Fig. 6) except: more maxillary teeth, ventrals and subcaudals, and relatively longer tail length in specimens KFBG 2002.01, SYS r001515, 2017 from Dawuling Forestry Station and SYS r000538 from Mt. Wuhuang; in the three female specimens from the same 
locality (Heishiding Nature Reserve) as the holotype, there are 17 maxillary teeth (vs. 16 maxillary teeth) and fewer subcaudals, 56 (broken tail) in SYS r000720, 69 in SYS r001350, 70 in SYS r001525 (vs. 76 in the male holotype).

Distribution and habits. Opisthotropis hungtai sp. nov. is currently known from Heishiding Nature Reserve (ca 300 m a.s.l.) and Dawuling Forestry Station (ca 900 m a.s.l.) in western Guangdong, and Mt. Wuhuang (ca $500 \mathrm{~m}$ a.s.l.) in southeastern Guangxi.

The specimen from Mt. Wuhuang was collected in a rocky stream. Besides, specimens from Heishiding Nature Reserve were found in pelitic gutterways along the dirt path, and specimens from Dawuling Forestry Station were collected in a pelitic stream. The collection sites were all surrounded by well-preserved, dense deciduous forest.

\section{Discussion}

As a representative snake group of the Oriental Realm, the mountain Keelback genus Opisthotropis receives more attention for its important role as an environmental indicator. Mountain Keelbacks are generally adapted to rocky forest streams (Wang et al. 2017a, b). However, species delimitations in this genus are still poorly resolved. The true diversity of Opisthotropis was underestimated, which is fatal for appropriate conservation of these habitat specialists. According to the integrative taxonomic approach, i.e., combining detailed morphological and molecular analyses, used in this study, the record of $O$. maculosa should be removed from the Chinese herpetofauna. So far, the true $O$. maculosa is restricted to northern Thailand, with only a single individual recorded. Opisthotropis haihaensis occurs in the mountain regions along the ChinaVietnam border with only two female specimens recorded up to now, and O. hungtai is known only from the hilly regions between Guangxi and Guangdong of southern China. Extended surveys are urgently needed over the broad region from southern China to northern Thailand to investigate the distribution and the population status of these three species. Due to their beautiful color patterns, the snakes are in high demand in the animal trade market (Ziegler et al. 2019), and they must be evaluated for inclusion in one of the conservation categories in the IUCN Red List of Threatened Species.

The discovery of Opisthotropis hungtai sp. nov. brings the total number of species of Opisthotropis to 24. Nevertheless, with regard to recent phylogenetic results (Ren et al. 2017; Wang et al. 2017; Ziegler et al. 2019; this study), the relationships of clades within this genus still remain largely unresolved. As the mitochondrial CYTB gene is unable to generate significant support values, further work employing multilocus nuclear-gene and matrilineal mtDNA genealogy is recommended to decipher this puzzle. In addition, the similar appearance of $O$. maculosa, O. haihaensis and O. hungtai, together with their distant genetic divergence, indicates cryptic speciation in the genus Opisthotropis. The non-monophyletic relationships between $O$. maculosa and the clade composed of $O$. hungtai and $O$. haihaensis in our phylogenetic tree indicate that identical or similar phenotypes have evolved independently. 


\section{Key to the species included in Opisthotropis maculosa sensu lato}

1 Prefrontal touching supraocular O. maculosa

- Prefrontal not touching supraocular 2

2 Supralabials eight, the second last one significantly enlarged; maxillary teeth $22-24$

O. haibaensis

- Supralabials seven, the second last one slightly enlarged; maxillary teeth $16-18$

O. hungtai

\section{Acknowledgements}

We would like to thank Can-Rong Lin, Qing Du, Run-Lin Li, Jian Zhao, and Zhi Xiao, for their help in the field. This work was supported by the Scientific Expedition of Biological Resources of Yunkai Mountains in Guangdong Province (No. 2018B030320001) and the Specimen Platform of Ministry of Science and Technology, P.R. China, teaching specimens sub-platform (No.2005DKA21403JK).

\section{References}

Angel F, Bourret R (1933) Sur une petite collection de serpents du Tonkin. Descriptions d'espèces nouvelles. Bulletin de la Société Zoologique de France 58(3-4): 129-140.

Boulenger GA (1888) Description of two new snakes from Hong Kong and note on the dentition of Hydrophis viperina. Annals and Magazine of Natural History 2(6): 43-45. https:// doi.org/10.1080/00222938809460874

Boulenger GA (1899) On a collection of reptiles and batrachians made by Mr. J.D. La Touche in N.W. Fokien, China. Proceedings of the Zoological Society of London 1899: 159-172. [pls. 16-19]

Boulenger GA (1903) Descriptions of new snakes in the collection of the British Museum. Annals and Magazine of Natural History, Series 7, 12(69): 350-354. https://doi. org/10.1080/00222930308678866

Boulenger GA (1914) Descriptions of new species of snakes in the collection of the British Museum. Annals and Magazine of Natural History, Series 8, 14(84): 482-485. https://doi. org/10.1080/00222931408693606

David P, Pauwels OSG, Nguyen TQ, Vogel G (2015) On the taxonomic status of the Thai endemic freshwater snake Parahelicops boonsongi, with the erection of a new genus (Squamata: Natricidae). Zootaxa 3948(2): 203-217. https://doi.org/10.11646/ zootaxa.3948.2.3

David P, Pham TC, Nguyen QT, Ziegler T (2011) A new species of the genus Opisthotropis Günther, 1872 (Squamata: Natricidae) from the highlands of Kon Tum Province, Vietnam. Zootaxa 2758: 43-56. https://doi.org/10.11646/zootaxa.2758.1.3 
Günther ACLG (1872) Seventh account of new species of snakes in the collection of the British Museum. Annals and Magazine of Natural History 9(4): 13-37. https://doi. org/10.1080/002229372011951771

Pope CH (1928) Seven new reptiles from Fukien Province, China. American Museum Novitates 320: 1-6.

Ronquist F, Teslenko M, Van Der Mark P, Ayres DL, Darling A, Höhna S, Larget B, Liu L, Suchard MA, Huelsenbeck JP (2012) MrBayes 3.2: efficient Bayesian phylogenetic inference and model choice across a large model space. Systematic Biology 61(3): 539-542. https://doi.org/10.1093/sysbio/sys029

Ren JL, Wang K, Jiang K, Guo P, Li JT (2017) A new species of the Southeast Asian genus Opisthotropis (Serpentes: Colubridae: Natricinae) from western Hunan, China. Zoological Research 38(5): 251-263.

Ren JL, Wang K, Guo P, Wang YY, Nguyen TT, Li JT (2019) On the generic taxonomy of Opisthotropis balteata (Cope, 1985) (Squamata: Colubridae: Natricinae): taxonomic revision of two natricine genera. Asian Herpetological Research 10(2): 105-128.

Stuart BL, Chuaynkern Y (2007) A new Opisthotropis (Serpentes: Colubridae: Natricinae) from Northeastern Thailand. Current Herpetology 26(1): 35-40. https://doi.org/10.3105/13455834(2007)26[35:ANOSCN]2.0.CO;2

Silvestro D, Michalak I (2012) RaxmlGUI: a graphical front-end for RAxML. Organisms Diversity and Evolution 12(4): 335-337. https://doi.org/10.1007/s13127-011-0056-0

Tamura K, Stecher G, Peterson D, Filipski A, Kumar S (2013) MEGA6: molecular evolutionary genetics analysis, version 6.0. Molecular Biology and Evolution 30(12): 2725-2729. https://doi.org/10.1093/molbev/mst197

Teynié A, Lottier A, David P, Nguyen TQ, Vogel G (2014) A new species of the genus Opisthotropis Günther, 1872 from northern Laos (Squamata: Natricidae). Zootaxa 3774(2): 165182. https://doi.org/10.11646/zootaxa.3774.2.4

Wang YY, Guo Q, Liu ZY, Lyu ZT, Wang J, Luo L, Sun YJ, Zhang YW (2017a) Revisions of two poorly known species of Opisthotropis Günther, 1872 (Squamata: Colubridae: Natricinae) with description of a new species from China. Zootaxa 4247(4): 391-412. https:// doi.org/10.11646/zootaxa.4247.4.3

Wang J, Lyu ZT, Zeng ZC, Liu ZY, Wang YY (2017b) Re-description of Opisthotropis laui Yang, Sung and Chan, 2013 (Squamata: Natricidae). Asian Herpetological Research 8(1): 70-74. https://doi.org/10.16373/j.cnki.ahr.160032

Yang JH, Sung YH, Chan BPL (2013) A new species of the genus Opisthotropis Günther, 1872 (Squamata: Colubridae: Natricinae) from Guangdong Province, China. Zootaxa 3646(3): 289-296. https://doi.org/10.11646/zootaxa.3646.3.7

Yang JH, Wang YY, Zhang B, Lau MWN, Chou WH (2011) Revision of the diagnostic characters of Opisthotropis maculosa Stuart and Chuaynkern, 2007 with notes on its distribution and variation, and a key to the genus Opisthotropis (Squamata: Natricidae). Zootaxa 2785: 61-68. https://doi.org/10.11646/zootaxa.2785.1.4

Zhao EM (1999) Diagnoses of a new frog and a new snake from China. Sichuan Journal of Zoology 18(3): 183. 
Zhao EM, Jiang YM, Huang QY (1978) Three new snake species in China. Material for Herpetological Researches 4: 21.

Ziegler T, David P, Thana VN (2008) A new natricine snake of the genus Opisthotropis from Tam Dao, Vinh Phuc Province, northern Vietnam (Squamata, Colubridae). Zoosystematics and Evolution 84(2): 197-203. https://doi.org/10.1002/zoos.200800004

Ziegler T, Pham CT, Nguyen TV, Nguyen TQ, Wang J, Wang YY, Stuart BL, Le MD (2019) A new species of Opisthotropis from northern Vietnam previously misidentified as the Yellowspotted Mountain Stream Keelback O. maculosa Stuart \& Chuaynkern, 2007 (Squamata: Natricidae). Zootaxa 4613(3): 579-586. https://doi.org/10.11646/zootaxa.4613.3.9 